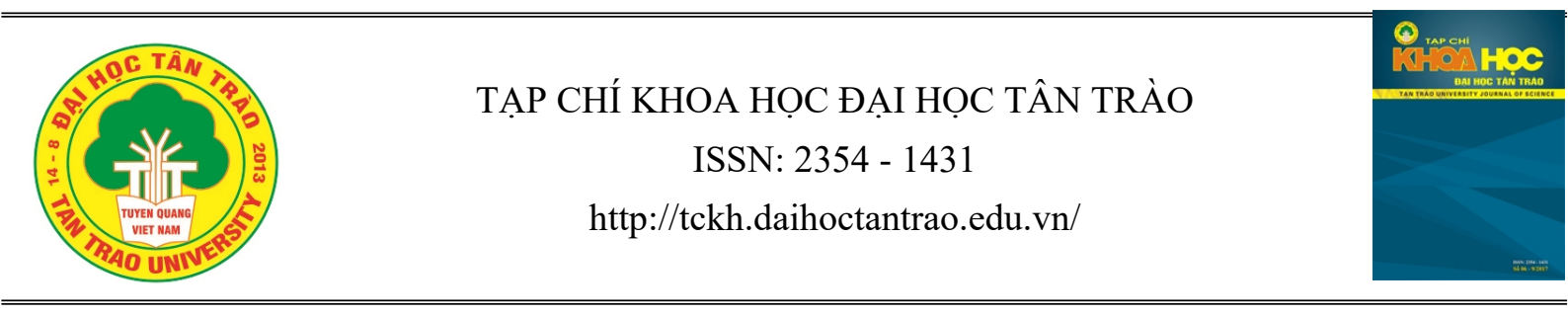

\title{
Cơ sở lý luận về phát triển năng lực tổ chức hoạt động trải nghiệm sáng tạo cho sinh viên ngành Giáo dục Tiểu học
}

\author{
$H a ̀$ Mỹ Hạnh ${ }^{a^{*}}$ \\ ${ }^{a}$ Trưòng Đại học Tân Trào \\ *Email: hamyhanhedu@gmail.com
}

\section{Thông tin bài viết}

Ngày nhận bài:

04/8/2019

Ngày duyệt đăng:

$10 / 12 / 2019$

Tì khóa:

Phát triển năng lực, năng lực tổ chưc, hoạt động trải nghiệm sáng tao, Truòng Đại học Tân Trào

\section{Tóm tắt}

Để đáp ứng yêu cầu đổi mới Chương trình giáo dục phổ thông, việc nghiên cứu cơ sở lý luận về phát triển năng lực tổ chức hoạt động trải nghiệm sáng tạo cho sinh viên ngành giáo dục tiểu học là rất cần thiết. Trong khuôn khổ bài viết này tác giả đi sâu phân tích: Khái niệm, đặc điểm tâm lý sinh, mục tiểu, nội dung, phương pháp và những con đường phát triển năng lực tổ chức hoạt động trải nghiệm sáng tạo cho sinh viên ngành giáo dục tiểu học ở trường Đại học Tân Trào (ĐHTT).

\section{1. Đặt vấn đề}

Hoạt động trải nghiệm sáng tạo là hoạt động mang tính tích hợp và phân hóa cao, được thực hiện dưới nhiều hình thức đa dạng, đòi hỏi sự phối hợp, liên kết nhiều lực lượng giáo dục trong và ngoài nhà trường. Hoạt động trải nghiệm sáng tạo giúp học sinh học tích cực, hiệu quả, thông qua hoạt động này hình thành và phát triển ở học sinh các phẩm chất, năng lực đặc thù: năng lực thích ứng với cuộc sống, năng lực thiết kế và tổ chức hoạt động, năng lực định hướng nghề nghiệp.

Hoạt động trải nghiệm sáng tạo được xác định là một trong những hoạt động trong chương trình học tập của học sinh từ tiểu học, THCS đến học sinh THPT. Chính vì thế, chương trình Hoạt động trải nghiệm sáng tạo được chính thức ban hành kèm theo Thông tư số 32/2018/TT-BGDĐT ngày 26 tháng 12 năm 2018 của Bộ trưởng Bộ Giáo dục và Đào tạo về việc “ban hành chuoong trình giáo dục phổ thông"[3]. Để đạt được mục tiêu mà chương trình giáo dục phổ thông mới đòi hỏi người giáo viên phải có năng lực tổ chức hoạt động, muốn vậy ngay từ khi đào tạo nghề trong các trường chuyên nghiệp thì người học cần được trang bị đầy đủ kiến thức, kĩ năng, thái độ về tổ chức hoạt động trải nghiệm sáng tạo.

Trường Đại học Tân Trào là cơ sở giáo dục có truyền thống đào tạo, bồi dưỡng giáo viên khối ngành sư phạm, trong đó sinh viên ngành GDTH vẫn chiếm đa số. Trong những năm qua, nhà trường rất chú trọng việc đổi mới phương pháp, bổ sung và chỉnh sửa chương trình đào tạo nhằm đáp ứng yêu cầu giáo dục phổ thông. Để đáp ứng yêu cầu đổi mới giáo dục phổ thông bài viết đi sâu phân tích cơ sở lý luận về phát triển năng lực tổ chức hoạt động trài nghiệm sáng tạo cho sinh viên ngành giáo dục tiểu học Trường Đại học Tân Trào.

2. Lý luận về phát triển năng lực tổ chức hoạt động trải nghiệm sáng tạo cho sinh viên ngành giáo dục tiểu học Trường Đại học Tân Trào

\subsection{Khái niệm công cụ}

\subsubsection{Hoạt động trải nghiệm sáng tạo}

* Định nghĩa:

Theo định nghĩa trong Chương trình giáo dục phổ thông của Bộ GD\&ĐT ban hành: Hoạt động trải 
nghiệm và Hoạt động trải nghiệm, huớng nghiệp là hoạt động giáo dục do nhà giáo dục định huoóng, thiết kế và huoóng dẫn thưc hiện, tạo co hội cho học sinh tiếp cận thực tế, thể nghiệm các cảm xúc tích cưc, khai thác nhũng kinh nghiệm đã có và huy động tổng hợp kiến thức, kĩ năng của các môn học để thực hiện nhũng nhiệm vu được giao hoặc giải quyết nhũng vấn đề của thực tiễn đời sống nhà truờng, gia đình, xã hội phù hơp với lưa tuổi; thông qua đó, chuyển hoá nhũng kinh nghiệm đã trải qua thành tri thức mói, hiểu biết mói, kĩ năng mới góp phần phát huy tiềm năng sáng tạo và khả năng thich ứng với cuộc sống, môi truờng và nghề nghiệp tuoong lai [1].

Trên có sở nghiên cứu và kế thừa quan điểm của các nhà khoa học theo tác giả hoạt động trải nghiệm sáng tạo có thể hiểu là hoạt động giáo dục, trong đó, duới sự huớng dân và tổ chức của nhà giáo dục, tùng cá nhân học sinh được tham gia trục tiếp vào các hoạt động thực tiến khác nhau của đòi sống gia đình, nhà truòng cũng nhu ngoài xã hội với tu cách là chủ thể của hoạt động, qua đó phát triển năng lục thực tiễn, phẩm chất nhân cách và phát huy tiềm năng sáng tạo của cá nhân mình.

2.1.2. Phát triển năng lực tổ chưc hoạt động trải nghiệm sáng tạo cho sinh viên ngành giáo dục tiểu học

Phát triển (năng lực) NL tổ chức hoạt động trải nghiệm sáng tạo (HĐTNST) cho sinh viên (SV) diễn ra trong thời gian dài dưới sự tác động, định hướng, cố vấn của các lực lượng giáo dục trong, ngoài nhà trường và sự tự rèn luyện của bản thân. Về bản chất là quá trình biến đổi về mặt nhận thức và các kĩ năng, thái độ của $\mathrm{SV}$ từ thấp đến cao theo chiều hướng hoàn thiện dần thông qua con đường dạy học và giáo dục. Cụ thể diễn ra theo những bước sau:

Thú nhất: Thông qua dạy học, giáo dục cung cấp kiến thức làm thay đổi về mặt nhận thí̛c.

Thông qua hoạt động dạy học tích hợp, lồng ghép và tổ chức các hoạt động giáo dục giúp $\mathrm{SV}$ có tri thức hiểu biết về các vấn đề tổ chức HĐTNST: Hiểu biết về thiết kế hoạt động trong đó hiểu được cách xác định được mục tiêu cho các hoạt động cá nhân và hoạt động nhóm; xác định được nội dung và cách thức thực hiện hoạt động cá nhân, hoạt động nhóm và dự kiến được thời gian thực hiện nhiệm vụ. Nắm được cách thực hiện kế hoạch và điều chỉnh hoạt động linh hoạt, mềm dẻo trong quá trình tổ chức HĐTNST. Có kiến thức về tìm kiếm sự hỗ trợ khi cần thiết và giải quyết mâu thuẫn nảy sinh trong hoạt động; xử lý tình huống. Hiểu rõ về cách đánh giá HĐTNST.

Thư hai: Thông qua dạy học, giáo duc rèn luyện kĩ năng, thái độ tổ chức HĐTNST. Phát triển NL tổ chức HĐTNST cho SV trên cơ sở nhận thức đúng và đủ về tri thức tổ chức HĐTNST. Từ đó, mỗi SV tích cực, rèn luyện kĩ năng, thái độ tổ chức HĐTNST và phát huy những ưu điểm của bản thân để biến những tri thức, kinh nghiệm lịch sử xã hội thành hành động của bản thân dưới sự hướng dẫn, định hướng của các lực lượng giáo dục (gia đình, nhà trường và xã hội). Thông qua con đường dạy học tích hợp vào trong các môn học trên lớp, tổ chức các hoạt động giáo dục và sử dụng hệ thống các phương pháp dạy học, giáo dục tích cực giúp SV phát huy tính tích cực, tự giác, chủ động, sáng tạo, rèn luyện thói quen, tinh thần tự giác, và rèn luyện các kĩ tổ chức HĐTNST.

Buớc ba: Kiểm tra đánh giá kết quả phát triển năng lục tổ chức HĐTNST. Phát triển tổ chức HĐ TNST là một quá trình lâu dài thể hiện sự tiến bộ của $\mathrm{SV}$ về tổ chức HĐTNST. Vì thế, việc kiểm tra, đánh giá kịp thời có ý nghĩa rất quan trọng nó có tác dụng tạo động lực cho SV phát triển năng lực tổ chức HĐTNST, giúp GV, SV luôn giữ được mối "liên hệ ngược" để thấy được điểm mạnh, điểm yếu từ đó giúp họ có điều chỉnh phù hợp nhằm nâng cao kết quả phát triển năng lực tổ chức HĐTNST cho SV ngành giáo dục tiểu học.

Từ sự phân tích trên và xem xét dưới góc độ giáo dục học tác giả quan niệm: Phát triển năng lực tổ chức hoạt động trải nghiệm sáng tạo cho sinh viên ngành giáo dục tiểu học là một quá trình hoàn thiện hệ thống tri thức, kĩ năng, thái độ trong thiết kế, thực hiện, đánh giá hoạt động thực tiễn ở sinh viên theo huớng đáp ứng yêu cầu hoạt động trải nghiệm thông qua con đuờng day học và giáo duc.

Phát triển NLHĐXH cho SV ngành giáo dục tiểu học (GDTH) bao hàm:

+ Phát triển và hoàn thiện về mặt kiến thức tổ chức HĐTNST

+ Phát triển và hoàn thiện về kĩ năng tổ chức HĐTNST.

+ Phát triển và hoàn thiện về thái tổ chức HĐTNST.

+ Quá trình hoàn thiện tri thức, kĩ năng, thái độ được tiến hành thông qua con đường dạy học và giáo dục.

\section{2. Đặc điểm của sinh viên ngành giáo dục tiểu học}

Trên cơ sở nghiên cứu và kế thừa nghiên cứu của các nhà khoa học, tác giả đưa ra những đặc điểm của 
sinh viên nói chung và sinh viên ngành giáo dục tiểu học Trường Đại học Tân Trào nói riêng như sau:

\subsection{1. Đặc điểm tâm lý}

Bên cạnh những đặc điểm tâm lý lứa tuổi chung của thanh niên và đặc điểm tâm lí chung của giới sinh viên như tính ổn định của ý thức về bản thân, về quan hệ xã hội, khả năng đánh giá và tự đánh giá, sự trưởng thành của tình cảm đặc trưng giới, tư duy logic và ý chí có tính chủ động, sự phát triển cao của nhu cầu nhận thức, nhu cầu học hỏi, nhu cầu giao tiếp xã hội, nhu cầu lao động nghề nghiệp, nhu cầu tự khẳng định, tính độc lập, tính phiêu lưu mạo hiểm và ra thử thách, ham thích khám phá và làm việc theo lối mới, nhiều hoài bão và ước mơ trong đó có ước mơ sáng tạo và làm nên sự nghiệp, song cũng có những nét bồng bột, thiếu chín chắn, dễ sai lầm, hay tự ái, dễ nản chí, dễ thất vọng khi thất bại, dễ hoài nghi khi bị lừa dối, dễ nghĩ liều và làm liều khi bế tắc V.v.. thì sinh viên ngành giáo dục tiểu học có những đặc điểm tâm lí đặc trưng riêng, đó là: $1 /$ Tư duy và nhận thức của các em có những đặc điểm của tư duy sư phạm, tức là tư duy khoa học nhưng giàu hình tượng và xúc cảm bởi tính chất của nghề sư phạm tác động đến; 2/ Tình cảm nghề nghiệp của sinh viên ngành giáo dục tiểu học tương đối ổn định do thế giới trẻ em mang lại. 3/ Nhu cầu của sinh viên ngành giáo dục tiểu học mang tính xã hội cao và nhu cầu bậc cao chi phối các em; 4/ Ý chí và nghị lực của các em chủ yếu do mức độ định hướng nghề nghiệp và thích ứng nghề chi phối; $5 /$ Tâm vận động của nghề dạy học về nguyên tắc là phát triển tốt vì lao động của nghề là hỗn hợp cả trí óc và thể chất; 6/ Đặc điểm chú ý, trí nhớ và trị giác của sinh viên tương đối hoàn thiện, đạt đến độ chín

\subsection{2. Đặc điểm học tập}

Sinh viên ngành Giáo dục tiểu học có một số đặc điểm học tập chính sau đây: $1 /$ Sinh viên sư phạm tiểu học là người học có kinh nghiệm học tập, có thói quen học tập có hệ thống và đa số có kĩ năng học tập cơ bản như đọc tài liệu, tìm và khai thác thông tin ở thư viện hay trên : mạng, biết học hỏi qua chia sẻ ở nhóm bạn hoặc trên diễn đàn, hội thảo, hội nghị...; 2/ Sinh viên là người học trưởng thành nên kinh nghiệm sống đã đầy đủ và ít nhiều những tiền lệ trong kinh nghiệm sống cũng ảnh hưởng đến học tập: $3 /$ Khả năng đáp ứng các chiến lược học tập hiện đại của sinh viên sư phạm tiểu học nhìn chung là thấp: 4/ Phong cách học tập của sinh viên sư phạm tiểu học nói chung chưa phong phú, chưa sinh động: 5/ Thái độ học tập của sinh viên sư phạm tiểu học nói chung là tốt và tích cực.

Ngoài ra sinh viên ngành giáo dục tiểu học Trường Đại học Tân Trào cũng có đặc trưng riêng do tác động của môi trường sống. Phân lớn các em rất thật thà, chất phát, luôn cần cù, chịu khó, sáng tạo trong các hoạt động học tập. Tuy nhiên, còn một bộ phận không nhỏ các em còn chưa "xông xáo" trong tổ chức các hoạt động, kĩ năng giao tiếp, ứng xử tình huống chưa thật sự nhạy bén, kĩ năng nhận xét đánh giá các hoạt động vẫn còn hạn chế. Việc phát triển năng lực tổ chức hoạt động trải nghiệm sáng tạo cho sinh viên ngành giáo dục tiểu học Trường Đại học Tân Trào là rất cần thiết.

\subsection{Mục tiêu phát triển năng lục tổ chức hoạt} động trải nghiệm sáng tạo

Việc xác định mục tiêu phát triển năng lực tổ chức HĐTNST cho SV dựa trên cơ sở mục tiêu giáo dục bậc học, yêu cầu thực tiễn phát triển nguồn nhân lực trong thời kỳ mới và dựa vào cơ sở lý luận và thực tiễn. Phát triển năng lực tổ chức HĐTNST cho SV ngành giáo dục tiểu học hướng tới ba mục tiêu cụ thể sau đây:

- Phát triển kiến thức tổ chức HĐTNST: Kiến thức tổ chức HĐTNST cho sinh viên ngành giáo dục tiểu học trường Đại học Tân Trào cũng như các sinh viên sư phạm đó là những kiến thức về thiết kế hoạt động; thực hiện và điều chỉnh hoạt động; và đánh giá hoạt động trải nghiệm của học sinh.

- Phát triển kĩ năng tổ chức HĐTNST: Phát triển hệ thống kĩ năng tổ chức HĐTNST cho sinh viên ngành giáo dục tiểu học trường Đại học Tân Trào ngoài kĩ năng tổ chức các hoạt động giáo dục còn chú ý tới phát triển kĩ năng đặc thù bản sắc văn hóa địa phương Tuyên Quang.

- Phát triển thái độ tổ chức HĐTNST: đảm bảo cho quá trình phát triển năng lực tổ chức HĐTNST đạt kết quả cao.

\subsection{Nội dung phát triển năng lục tổ chức hoạt động trải nghiệm sáng tạo}

Thông qua quá trình dạy học và giáo dục, dựa vào mục tiêu giáo dục bậc đại học, đặc điểm tâm sinh lý của sinh viên, đặc thù của địa phương việc phát triển năng lực tổ chức hoạt động trải nghiệm sáng tạo cho sinh viên ngành giáo dục tiểu học trường Đại học Tân Trào gồm những nội dung sau:

* Phát triển hệ thống kiến thức tổ chưc HĐTNST:

- Hiểu biết về thiết kế hoạt động trong đó hiểu được cách xác định được mục tiêu, nội dung, cách thức thực 
hiện hoạt động cá nhân, hoạt động nhóm và dự kiến được thời gian thực hiện nhiệm vụ. Nắm được cách thực hiện kế hoạch, điều chỉnh hoạt động linh hoạt, mềm dẻo trong quá trình tổ chức HĐTNST. Có kiến thức về tìm kiếm sự hỗ trợ khi cần thiết, giải quyết mâu thuẫn nảy sinh trong hoạt động; xử lý tình huống. Hiểu rõ về cách đánh giá HĐTNST.

- Hiểu biết về những chủ đề của HĐTNST trong đó có những hoạt động gắn liền với địa phương mang tính đặc thù riêng: bản sắc văn hóa tỉnh Tuyên Quang (Hát then, ẩm thực, phong tục tập quán địa phương); Những địa danh về du lịch lịch sử: du lịch sinh Thái Tuyên Quang.

* Phát triển kĩ năng tổ chức HĐTNST:

- Kĩ năng thiết kế hoạt động

+ Xác định được mục tiêu cho các hoạt động cá nhân và hoạt động nhóm.

+ Xác định được nội dung và cách thức thực hiện hoạt động cá nhân, hoạt động nhóm

+ Dự kiến được thời gian thực hiện nhiệm vụ.

- Kĩ năng thực hiện kế hoạch và điều chỉnh hoạt động

+ Chỉ đạo việc thực hiện được kế hoạch

+ Biết tìm sự hỗ trợ khi cần thiết

+ Biết huy động người khác tham gia hoạt động

+ Biết cách giải quyết mâu thuẫn nảy sinh trong hoạt động.

+ Xử lý tình huống

- Đánh giá hoạt động

+ Nêu được ý nghĩa của hoạt động đối với cá nhân và tập thể.

+ Chỉ ra được sự tiến bộ của học sinh sau hoạt động.

+ Chỉ ra được những điểm cần rút kinh nghiệm trong tổ chức hoạt động và sự tích cực hoạt động của cá nhân, nhóm.

* Phát triển thái độ tổ chức HĐTNST:

+Tôn trọng, ủng hộ và sẵn sàng chia sẻ với học sinh

+ Lịch sự, nhã nhặn, cởi mở trong quan hệ giao tiếp.

+ Vui vẻ giúp đỡ, khích lệ học sinh tham gia vào các hoạt động

2.5. Phương pháp phát triển năng lục tổ chúc hoạt động trải nghiệm sáng tạo

* Phương pháp giải quyết vấn đề (GQVĐ)
GQVĐ là một phương pháp giáo dục nhằm phát triển năng lực tư duy, sáng tạo, GQVĐ. Sinh viên được đặt trong tình huống có vấn đề, thông qua việc GQVĐ giúp sinh viên lĩnh hội tri thức, $\mathrm{KN}$ và phương pháp.

Phương pháp trên được tiến hành theo các bước cụ thể như sau:

\section{Bước 1: Nhận biết vấn đề}

Trong bước này GV cần phân tích tình huống đặt ra giúp sinh viên nhận biết được vấn đề để đạt yêu cầu, mục đích đặt ra. Do đó, vấn đề ở đây cần được trình bày rõ ràng, dễ hiểu.

\section{Bước 2: Tìm phương án giải quyêt}

Để tìm ra các phương án GQVĐ, SV cần so sánh, liên hệ với cách GQVĐ tương tự hay kinh nghiệm đã có cũng như tìm phương án giải quyết mới. Các phương án giải quyết đã tìm ra cần được sắp xếp, hệ thống hóa để xử lí ở giai đoạn tiếp theo. Khi có khó khăn hoặc không tìm được phương án giải quyết thì cần quay trở lại việc nhận biết vấn đề để kiểm tra lại và hiểu vấn đề.

Buớc 3: Quyết định phương án giải quyết

GV cần quyết định phương án GQVĐ, khi tìm được phải phân tích, so sánh, đánh giá xem có thực hiện được việc GQVĐ hay không. Nếu có nhiều phương án giải quyết thì cần so sánh để xác định phương án tối ưu. Nếu các phương án đã đề xuất mà không giải quyết được vấn đề thì tìm kiếm phương án giải quyết khác. Khi quyết định được phương án thích hợp là đã kết thúc việc GQVĐ.

\section{* Phương pháp làm việc nhóm}

Thực chất của phương pháp này giáo viên tổ chức cho SV tham gia trao đổi, giải quyết về một vấn đề hoặc nội dung thuộc lĩnh vực HĐTNST theo nhóm, giảng viên kích thích $\mathrm{SV}$ tự giác, tích cực hợp tác để giải quyết nhiệm vụ đặt ra, trên cơ sở đó rút ra nhận xét, kết luận.

Phương pháp làm việc nhóm được chia ra làm hai loại: nhóm nhỏ và nhóm lớn. Nhóm nhỏ được sử dụng phổ biến trong quá trình dạy học, do phương pháp này nó đáp ứng rất tốt mục tiêu cải cánh - phát huy cao độ tính tích cực học tập của $\mathrm{SV}$. Làm việc nhóm còn là phương tiện học hỏi có tính chất dân chủ, mọi cá nhân được tự do bày tỏ quan điểm, tạo thói quen sinh hoạt bình đẳng, biết đón nhận quan điểm bất đồng, hình thành quan điểm cá nhân giúp $\mathrm{SV}$ rèn luyện kĩ năng sống trong tập thể, kĩ năng nói và biết lắng nghe người khác nói, kĩ năng giải quyết, kĩ năng hợp tác, kĩ năng phát biểu trước đám đông... Ngoài ra thảo luận theo 
nhóm còn giúp $\mathrm{SV}$ có kĩ năng tổ chức, quản lý, tự quản tạo điều kiện để các em tự trải nghiệm những thành công hay thất bại của bản thân.

Đặc điểm của phuoong pháp làm việc nhóm:

+ Mang tính tích cực, tự lực, tự giác rất cao và có tính chất chủ thể.

+ Đòi hỏi người học phải có kiến thức, kinh nghiệm, có đủ tài liệu tham khảo.

+ Người học tìm ra kiến thức mới, nhìn vấn đề nhiều góc cạnh khác nhau.

+ Về mặt xã hội: Thảo luận tạo điều kiện phát triển quan hệ giữa các thành viên nhóm: nghe, nói, tranh luận, lãnh đạo.

+ Về mặt giáo dục: Phát triển tính dân chủ, hợp tác ở SV.

\section{Tổ chức cho SV làm việc nhóm}

Nhiệm vu của GV: Lựa chọn và giao các nội dung, các vấn đề, công việc và các yêu cầu liên quan cho các nhóm SV thực hiện, nguồn tài liệu tham khảo tối thiểu,...

Thiết kế kịch bản cho nội dung làm việc nhóm.

Tham dự, hướng dẫn, đạo diễn, nhận xét và tổng kết các sản phẩm của từng nhóm. GV cần khẳng định những nội dung đúng, sửa chữa những nội dung chưa đúng hoặc "chốt" nội dung của vấn đề, dùng nó như một phương tiện để chuyển tải nội dung cốt lõi của chủ đề thảo luận.

Đánh giá, cho điểm phần chuẩn bị trình bày, thảo luận của từng nhóm hoặc từng $\mathrm{SV}$ và tích lũy vào kết quả cuối của môn học.

Nhiệm vu của $S V$ : Nhận nhiệm vụ, thời hạn hoàn thành, mẫu báo cáo hoạt động theo nhóm.

Nhóm trưởng lên kết hoạch, phân công công việc cho các thành viên, thời gian hoàn thành, triển khai kết hoạch, xem xét kết quả đạt được so với mục tiêu đề ra.

Trình bày báo cáo theo phân công.

Theo dõi, bổ sung, góp ý bài trình bày của các bạn cùng lớp, hoàn chỉnh bài trình bày đó hoặc của mình.

Hỏi, đối thoại, tranh luận những vấn đề đã trình bày tại buổi thảo luận.

Tự nhận xét đánh giá bài thảo luận.

Theo dõi sự nhận xét, tổng kết của GV để hoàn chỉnh bài trình bày tại buổi thảo luận.

\section{* Phuoong pháp đóng vai}

Đóng vai là phương pháp tổ chức cho $\mathrm{SV}$ thực hành, "làm thử" một số cách ứng xử nào đó trong một tình huống giả định. Đây là phương pháp nhằm giúp SV suy nghĩ sâu sắc về một vấn đề bằng cách tập trung vào một sự việc cụ thể mà các em vừa thực hiện hoặc quan sát được. Việc "diễn" không phải là phần chính của phương pháp này mà điều quan trọng là sự thảo luận sau phần diễn ấy.

Có thể tiến hành đóng vai theo các bước sau:

- Chuẩn bị:

+ GV chia nhóm, giao tình huống đóng vai cho từng nhóm và quy định rõ thời gian chuẩn bị, thời gian đóng vai.

+ Các nhóm thảo luận chuẩn bị đóng vai.

- Thực hành: Các nhóm lên đóng vai.

- Nhận xét, đánh giá.

\section{* Phuoong pháp tụ trải nghiệm}

Tự trải nghiệm dưới sự định hướng, tư vấn của $\mathrm{GV}$ sẽ giúp $S V$ rèn luyện khả năng tự tin trước người khác, kĩ năng giải quyết vấn đề. Tự trải nghiệm của $\mathrm{SV}$ giữ vai trò rất quan trọng, nó là nhân tố quyết định tới việc nâng cao NLHĐXH của SV. Bên cạnh đó, tự trải nghiệm còn góp phần nâng cao hoạt động trí tuệ của $\mathrm{SV}$ trong việc tiếp thu và hiểu tri thức về $\mathrm{HĐXH}$, rèn luyện cho SV kĩ năng độc lập suy nghĩ, độc lập giải quyết các vấn đề khó khăn trong quá trình học, giúp SV tự tin hơn trong cuộc sống của mình, thích ứng và bắt nhịp nhanh với những tình huống mới lạ mà cuộc sống hiện đại mang đến, kể cả những thách thức to lớn từ môi trường nghề nghiệp. Tự trải nghiệm của $\mathrm{SV}$ cần phải được tăng cường trong học tập trên lớp, trong thực hành thực tập chuyên môn, trong hoạt động giáo dục ngoài giờ lên lớp và tự rèn luyện của mỗi cá nhân $\mathrm{SV}$.

* Phuoong pháp rèn luyện

- Là phương pháp tổ chức cho SV được thể nghiệm ý thức, tình cảm của mình về các chuẩn mực xã hội trong các tình huống đa dạng của cuộc sống qua đó hình thành và củng cố được những hành vi phù hợp với các chuẩn mực xã hội đã được quy định.

- Tác dụng:

+ Tạo cơ hội cho người được giáo dục thâm nhập vào những tình huống đa dạng từ đơn giản đến phức tạp, từ dễ đến khó.

+ Tạo cơ hội cho người được giáo dục biến kết quả tập luyện (hành vi) thành thói quen bền vững.

- Trong quá trình giáo dục có thể tạo cơ hội cho người được giáo dục rèn luyện trong các tình huống: Đời sống tập thể; Hoạt động học tập, lao động; Sinh 
hoạt hàng ngày ở nhà, ở trường, xã hội; Các hoạt động xã hội nói chung, hoạt động từ thiện...

- Để tạo điều kiện cho người được giáo dục rèn luyện tốt cần:

+ Tận dụng những tình huống tự nhiên, tạo ra những tình huống thích hợp.

+ Kết hợp chặt chẽ với tự kiểm tra.

+ Tổ chức rèn luyện liên tục, có hệ thống.

+ Kết hợp tổ chức rèn luyện với tự tổ chức rèn luyện.

2.6. Con đưòng phát triển năng lục tổ chức hoạt động trải nghiệm sáng tạo

* Tổ chức dạy học trên lóp theo huoóng lồng ghép, tích hợp nội dung năng lực tổ chưc hoạt động trải nghiệm sáng tạo trong chuong trình dạy học thông qua các môn hoc chiếm wu thế

Hoạt động dạy học trên lớp là hoạt động giữ vai trò chủ đạo, định hướng cố vấn cho sự phát triển của $\mathrm{SV}$. Tùy theo nội dung, chương trình của từng môn học mà GV lựa chọn các phương pháp dạy học phù hợp nhằm phát triển tri thức, kĩ năng, thái độ tổ chức HĐTNST. GV có thể lựa chọn lồng ghép, tích hợp nội dung phát triển năng lực tổ chức HĐTNST trong chương trình dạy học thông qua các môn học chiếm ưu thế như: GDH, Nghi thức đội TNTP HCM, HĐGDNGLL, Giáo dục kĩ năng sống, Giáo dục lối sống... GV cần nghiên cứu nội dung dạy học từ đó thiết kế các tình huống dạy sinh viên chủ động, áp dụng các phương pháp dạy học tích cực để tạo dựng được sự liên kết giữa $\mathrm{SV}$ với nhau, chia sẻ, hợp tác, giúp đỡ lẫn nhau, cùng nhau bàn bạc, trao đổi thông tin, trao đổi những quan điểm cá nhân, xây dựng bầu không khí học tập thỏa mái, không căng thẳng, mệt mỏi từ đó cuốn hút $\mathrm{SV}$ tham gia vào hoạt động nhóm, lớp nhằm phát triển kĩ năng thiết kế, kĩ năng thực hiện kế hoạch và điều chỉnh hoạt động, kĩ năng xử lý các tình huống, kĩ năng đánh giá hoạt động... Như vậy, thông qua dạy học lồng ghép, tích hợp không những đảm bảo được mục tiêu môn học mà còn phát triển năng lực tổ chức HĐTNST cho sinh viên ngành giáo dục tiểu học trường Đại học Tân Trào.

\section{* Hoạt động tụ học của sinh viên}

Hoạt động tự học là con đường có nhiều thuận lợi để phát triển năng lực tổ chức HĐTNST bởi vì tính tích cực hoạt động của cá nhân là yếu tố quyết định trực tiếp đến việc phát triển nhân cách. Để hoạt động tự học của $\mathrm{SV}$ vừa đạt được mục tiêu môn học đề ra, vừa phát triển năng lực tổ chức hoạt động trải nghiệm sáng tạo đòi hỏi
GV phải phát huy được vai trò chủ đạo, định hướng, tư vấn cho hoạt động tự học của SV. GV thiết kế nhiệm vu tụ học của SV duoói dạng tổ chức các hoạt động trải nghiệm, khơi dậy sụ ham hiểu biết, tìm tòi sáng tạo trong $S V$ đồng thời đặt ra mục đích, yêu cầu rõ ràng của từng nhiệm vụ và thời gian phải hoàn thành. GV phải quan tâm sát sao, tư vấn, kiểm tra thường xuyên hoạt động tự học $\mathrm{SV}$, đôn đốc $\mathrm{SV}$ hoàn thành nhiệm vụ theo yêu cầu. Đối với SV cần chuẩn bị tốt động cơ, thái độ học tập, tinh thần, trách nhiệm để "tự chủ, tự chịu trách nhiệm" trong học tập một cách chủ động và có hiệu quả. Trong quá trình tự học $\mathrm{SV}$ cần suy nghĩ sáng tạo và mạnh dạn đưa ra ý kiến thắc mắc của mình mà không phụ thuộc vào $G V$ hay sách giáo trình.

\section{* Hoạt động giáo dục ngoài giờ lên lóp}

Trường Đại học Tân Trào có nhiều thế mạnh trong tổ chức các hoạt động ngoài giờ lên lớp cho sinh viên. Để phát triển năng lực tổ chức hoạt động trải nghiệm sáng tạo cho SV ngành giáo dục tiểu học thì các khoa, trung tâm và Đoàn, Hội...có nhiều hình thức: Hội thi, tham quan, giao lưu, tọa đàm, ngoại khóa... được tổ chức hằng năm là con đường thuận lợi cho việc phát triển năng lực tổ chức HĐTNST cho sinh viên.

Trong quá trình tổ chức hoạt động ngoại khóa cần chú ý giao nhiệm vụ thiết kế, tổ chức các hoạt động cho sinh viên; tạo sự hấp dẫn, đa dạng, phong phú để thu hút đông đảo $\mathrm{SV}$ tham gia đồng thời cũng cần phải chú ý phát huy tính tích cực, chủ động, sáng tạo của SV trong tổ chức hoạt động để hoạt động này cũng là một trong những con đường cơ bản trong quá trình phát triển năng lực tổ chức HĐTNST cho sinh viên.

* Hoạt động thực hành, thực tế tại các truò̀ng phổ thông

Hoạt động thực hành, thực tế tại các trường phổ thông cũng là một trong những con đường chiếm ưu thế để phát triển năng lực tổ chức HĐTNST cho sinh viên ngành tiểu học trường Đại học Tân Trào. Thông qua hoạt dộng này các em được tham gia vào thực tập chuyên môn, làm công tác chủ nhiệm đặc biệt là tổ chức các hoạt động trải nghiệm theo chủ đề cho học sinh tiểu học theo quy mô lớp, khối và toàn trường sẽ phát triển ở các em kiến thức, kĩ năng và thái độ tổ chức HĐTNST.

Để phát triển năng lực tổ chức HĐTNST cho sinh viên ngành giáo dục tiểu học giáo viên giao nhiệm vụ và gợi ý cho sinh viên một số các hoạt động theo chủ đề: Khám phá bản thân; Rèn luyện bản thân; Xây dựng 
nhà trường; Xây dựng cộng đồng; Chủ đề gắn với địa phương Tuyên Quang.

* Tổ chức các hoạt động thực tiễn

Hoạt động này sẽ cung cấp cho SV kiến thức thực tiễn gắn bó với đời sống, địa phương, cộng đồng mang tính tổng hợp nhiều lĩnh vực giáo dục, nhiều môn học; dễ vận dụng vào thực tế. Các hoạt động thực tiễn đặc thù cho SV bao gồm hoạt động:

- Trải nghiệm khám phá những văn hóa đặc sắc của đồng bào dân tộc thiểu số: về ẩm thực, trang phục, hát, nhà ở, lễ hội...

- Hoạt động tham quan các bảo tàng, di tích lịch sử địa phương.

- Hoạt động truyền thông giới thiệu về các khu du lịch sinh thái, du lịch cộng đồng, du lịch tâm linh gắn với tỉnh Tuyên Quang

- Tham gia vào các hoạt động xã hội, thiệt nguyện:

+ Tổ chức cho SV tham gia hoạt động vận động người dân tham gia vào giáo dục, cho con đến trường, góp sức cùng nhà trường phát triển giáo dục và giáo dục học sinh.

+ Tổ chức cho SV tham gia xóa mù chữ tại thôn bản, phổ cập giáo dục, nâng cao chất lượng giáo dục qua hoạt động mùa hè tình nguyện.

+ Tổ chức cho SV tham gia hoạt động vận động bà con dân tộc giữ gìn phát huy các giá trị di sản văn hóa dân tộc, bài trừ loại bỏ những phong tục tập quán lạc hậu, lỗi thời, tham gia phòng chống tệ nạn xã hội trên địa bàn miền núi.

+ Tổ chức cho SV tham gia hoạt động từ thiện trợ giúp những người yếu thế trong xã hội: Học sinh có hoàn cảnh khó khăn, học sinh chậm tiến, những người có hoàn cảnh đặc biệt cần sự trợ giúp, những gia đình có công với cách mạng, dân tộc.

+ Tổ chức cho SV tham gia hoạt động bảo vệ môi trường làm xanh, sạch đẹp, bảo vệ các giá trị văn hóa truyền thống dân tộc, môi trường văn hóa nhà trường, nơi công cộng,...
- Hoạt động chính trị xã hội; Hoạt động văn hóa, văn nghệ, thể dục, thể thao; Kỷ niệm các ngày lễ lớn, hoạt động giáo dục Pháp luật, giáo dục môi trường, giáo dục giới tính, giáo dục phòng chống tệ nạn xã hội, hoạt động vì cộng đồng, giáo dục truyền thống bản sắc văn hóa dân tộc; giữ gìn, bảo vệ biển đảo, biên giới, mùa hè tình nguyện...

- Các hình thức câu lạc bộ tại trường Đại học Tân Trào: Câu lạc giáo dục kĩ năng sông, câu lạc bộ võ thuật; Câu lạc bộ hát then, Câu lạc bộ Tiếng Anh...

Chính từ những đặc trưng của các hoạt động thực tiễn trên nên hoạt động này cũng là con đường có nhiều thuận lợi cho việc phát triển năng lực tổ chức HĐTNST cho sinh viên ngành giáo dục tiểu học trường Đại học Tân Trào.

\section{Kết luận}

Phát triển năng lực tổ chức hoạt động trải nghiệm sáng tạo cho sinh viên ngành giáo dục tiểu học là một quá trình hoàn thiện hệ thống tri thức, kĩ năng, thái độ trong thiết kế, thực hiện, đánh giá hoạt động thực tiễn ở sinh viên theo hướng đáp ứng yêu cầu hoạt động trải nghiệm thông qua con đường dạy học và giáo dục.

Nghiên cứu cơ sở lý luận về phát triển năng lực tổ chức hoạt động trải nghiệm sáng tạo cho sinh viên ngành giáo dục tiểu học ở trường Đại học Tân Trào là việc làm có ý nghĩa và thiết thực góp phần làm sáng tỏ những vấn đề lý luận trong phát triển năng lực tổ chức hoạt động trải nghiệm sáng tạo.

\section{TÀI LIỆU THAM KHẢO}

1. Bộ GD\&ĐT (2018), Chương trình Giáo dục phổ thông, Hoạt động trải nghiệm và hoạt động trải nghiệm, hướng nghiệp.

2. Nguyễn Tuấn Dũng và Nguyễn Minh Hợp (2002), Tù điển quản lý xã hội, NXB Đại học Quốc Gia, Hà Nội.

3. Thông tư số $32 / 2018 /$ TT-BGDĐT ngày 26 tháng 12 năm 2018 của Bộ trưởng Bộ Giáo dục và Đào tạo về việc ban hành chương trình giáo dục phổ thông" 


\section{Developing the capacity to organize creative experience activities for students of Primary Education}

Ha My Hanh

\section{Article info}

Recieved:

04/8/2019

Accepted:

$10 / 12 / 2019$

Keywords:

Developing capacity, organizational capacity, creative experience activities, Tan Trao University.

\begin{abstract}
In order to meet the requirements of reforming the general education program, it is necessary to study the theoretical basis for developing the capacity to organize creative experiences for primary education students. In this article, the author deeply analyzes Concepts, psychological characteristics, sub-items, content, methods and ways to develop organizational capacity for creative experience activities for students of Primary education at Tan Trao University.
\end{abstract}

